\title{
Effects of Shrubland Changes on Birds in the Intermountain West
}

We are integrating field surveys with information obtained from satellite imagery to determine how birds respond to the habitat changes in shrubland regions in the Intermountain West. Our objectives are to determine the primary causes that change shrubland habitats, the spatial and temporal scales at which shrubland landscapes change, and the mechanisms by which distribution and abundance of bird populations are influenced by habitat change.

\section{Top: False-color composite view of southeastern Idaho derived from satellite imagery. \\ Bottom: Landcover changes in the Snake River Birds of Prey National Conservation Area, in southwestern Idaho, were deter- mined by comparing satellite images taken in 1992 and 1979. Approximately $25 \%$ of the area experienced loss of shrub cover during this period (yellow and red colors), compared to $<10 \%$ of the area that increased in shrub cover (dark green).}

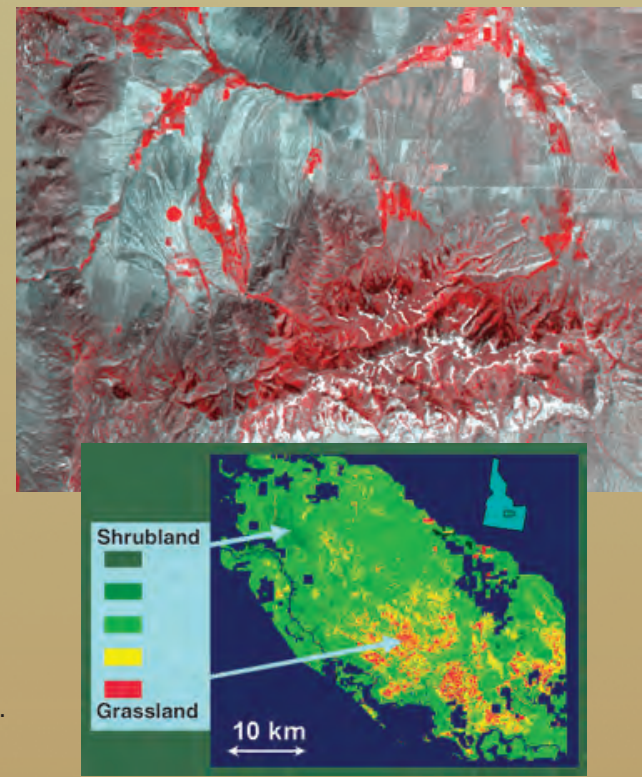

Habitat changes occur at different rates and are not uniform across a landscape. Shrubland habitats today are influenced by the surrounding habitats as well as by the rate and direction of habitat change from a previous time. Disturbance and land use practices influence spatial and temporal dynamics of the landscape in different ways. For example, wildfires might create a relatively abrupt change with welldefined boundaries across a landscape compared to the slower, less-visible changes caused by grazing.

We are determining the ways in which major disturbance and land use practices influence the landscape in shrubland regions from the digital data in a multi-temporal series of 10-year sequences in satellite imagery. By estimating each component of landscape composition, configuration, and change, we can better understand the spatial and temporal scales at which disturbance and land use practice influence these habitats.

Similarly, bird species that are dependent on shrubland ecosystems respond differently to different spatial and temporal changes in their habitats. We are combining our analysis of land cover change with the U.S. Geological Survey's Breeding Bird Survey to correlate local and large-scale habitat changes with short- and long-term population trends of birds.

Our analysis will help identify the mechanisms by which bird populations respond to habitat changes. The comprehensive data on types and rates of land cover changes and the response by obligate species of birds will be important to land managers who wish to reverse or mediate effects of land cover change in shrubland habitats of the Intermountain West.

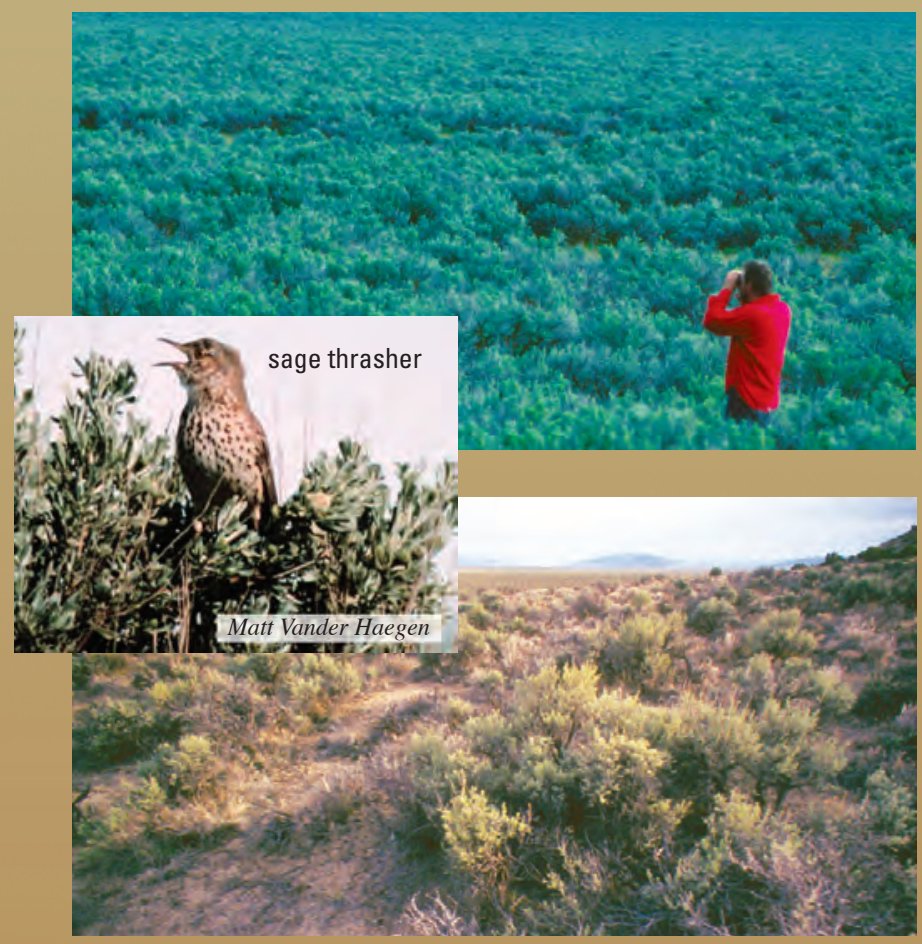

\section{Contacts:}

Steven T. Knick, USGS Forest and Rangeland Ecosystem Science Center, Snake River Field Station, 970 Lusk Street, Boise, ID 83706 (ph: 208-426-5208; email: steve_knick@usgs.gov)

Thomas R. Loveland, USGS EROS Data Center, Sioux Falls, SD 57198 (ph: 605-594-6066; email: loveland@usgs.gov) 